ENTREPRENEURSHIP AND SUSTAINABILITY ISSUES

ISSN 2345-0282 (online) http://jssidoi.org/jesi/

2020 Volume 7 Number 3 (March)

http://doi.org/10.9770/jesi.2020.7.3(63)
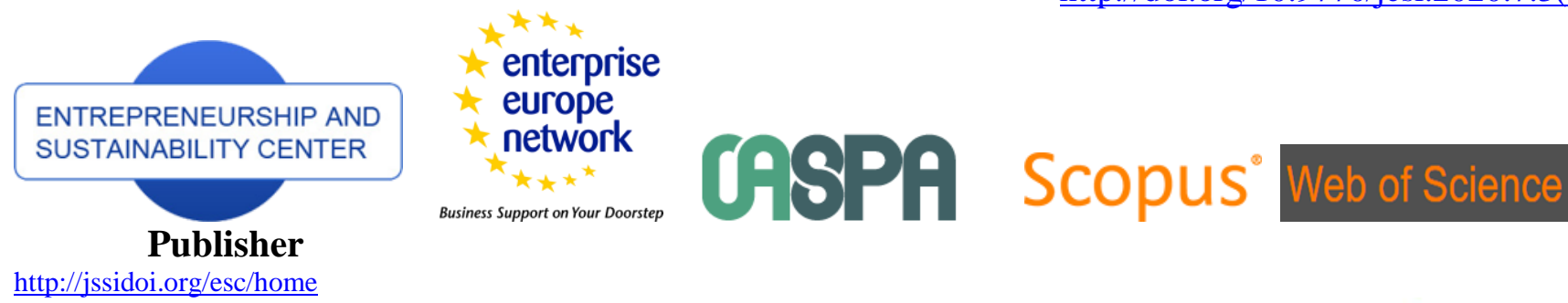

http://jssidoi.org/esc/home

\title{
OPTIMIZATION AND MANAGEMENT OF THE LECTURE TRAINING STRATEGY FOR STUDENTS
}

\author{
Elvira Ruzieva1, Aliya Nurgaliyeva ${ }^{2}$, Botagoz Duisenbayeva ${ }^{3}$, Dina Kulumbetova ${ }^{4}$, Mira Zhapbarkhanova $^{5}$ \\ 1,2,5 Narxoz University, Zhandosov st. 55, Almaty, Kazakhstan \\ ${ }^{3,4}$ Kazakh-Russian International University, Aiteke bi street 52, Aktobe, Kazakhstan \\ E-mails: ${ }^{1} \underline{\text { earuzieva@mail.ru }} ;{ }^{2} \frac{\text { aliya_mn@mail.ru }}{{ }^{5}{ }^{3} \text { mira.saparali@mail.ru }}$ duisenbayeva_b@mail.ru $;{ }^{4}$ dina_424@mail.ru ;
}

Received 19 June 2019; accepted 28 November 2019; published 30 March 2020

\begin{abstract}
Changing the needs of students in the consumption of information requires teachers to constantly search for new teaching methods, which, in turn, indicates the construction of their own learning strategy and its optimization. In this article, the authors present their own experience in developing a lecture learning strategy built on their own experience. Personal experience of teaching led to the emergence of the hypothesis that a change in the type of information provided (for example, from presentation to video, then to discussion, etc.) and the frequency of repetitions of important aspects of the topic can improve the learning. To test this hypothesis, the article attempted to use econometric modeling methods that made it possible to optimize the learning strategy taking into account the indicated factors.
\end{abstract}

Keywords: learning strategy; information assimilation factor; quality of learning; information perception

Reference to this paper should be made as follows: Ruzieva, E., Nurgaliyeva, A., Duisenbayeva, B., Kulumbetova, D., Zhapbarkhanova, M. 2020. Optimization of the lecture training strategy for students. Entrepreneurship and Sustainability Issues, 7(3), 2407-2418. http://doi.org/10.9770/jesi.2020.7.3(63)

JEL Classifications: I22, I25.

\section{Introduction}

With the increasing volatility of the market, and, consequently, the needs of employers, the issue of maximizing the assimilation of the information provided at classes in universities is becoming more and more relevant. The age of information technology, on the one hand, significantly expands the possibilities of students, and, on the other hand, significantly distracts from the "useful" information. This situation significantly changes the way students perceive information. If earlier learners could draw knowledge mainly through reading (visually), then today's sources are so multifaceted and diverse that information can be perceived through reading, watching videos, listening to audio literature and much more. Under these conditions, it is much more difficult for 


\section{ENTREPRENEURSHIP AND SUSTAINABILITY ISSUES}

ISSN 2345-0282 (online) http://jssidoi.org/jesi/

2020 Volume 7 Number 3 (March)

http://doi.org/10.9770/jesi.2020.7.3(63)

university teachers to determine the most optimal way to provide information in order to ensure maximum material digestibility. This task can be described as determining the optimal student learning strategy.

\section{Literature review}

An analysis of the scientific literature regarding the human's ability to perceive information shows that a variety and a constant focus on the attention of listeners are necessary for the best mastering of the material.

Studies of the biological and psychological aspects of human information perception occupy a rather long epoch of time. In particular, Albert Mehrabian in his publication "Non-Verbal Communication", published in 1972, outlined his "simple linear model": "General feeling $=7 \%$ verbal feeling $+38 \%$ auditory feeling $+55 \%$ feeling of mimicry" (Mehrabian and Ferris, 1967). In other words, the student absorbs 7\% of verbal material, 38\% of the material heard, and $55 \%$ of the material transmitted verbally.

Psychologist Jerome Bruner from New York University showed in his research that people only remember 10\% of what they hear and $20 \%$ of what they read, but about $80 \%$ of what they see and do (Samreen and Malik 2012). Anna Karpf refutes the percentage perception of information, referring to the views of some scientists. She writes "according to the philosopher Karl Popper, judgment is unscientific if it is observable or experienced. Imagine that I ask someone how to get to the bus stop for bus number 24 at nine in the morning. If I only paid $7 \%$ attention to the verbal content of their answer, we could easily wander in search of a bus at nine in the evening. It is completely absurd to suppose that words play such an insignificant role in human conversation, and a person so important: it clearly depends on who speaks with whom, when, where and why” (Karpf, 2014).

One way or another, one can say that a person can perceive information visually, verbally, and mimically. Much depends on the development of a certain memory in a person, all individually. Such an approach to the problem of mastering information forces teachers to apply various learning technologies in order to adapt them for different categories of students.

At the same time, a professor at Ohio State University, Edgar Dale, conducted a study according to which he taught the same educational material, but in various ways, he discovered and analyzed the ability to reproduce the material studied. The results of the study were published in the "Dale's cone of experience" in the form of the Dale pyramid (Figure 1). 


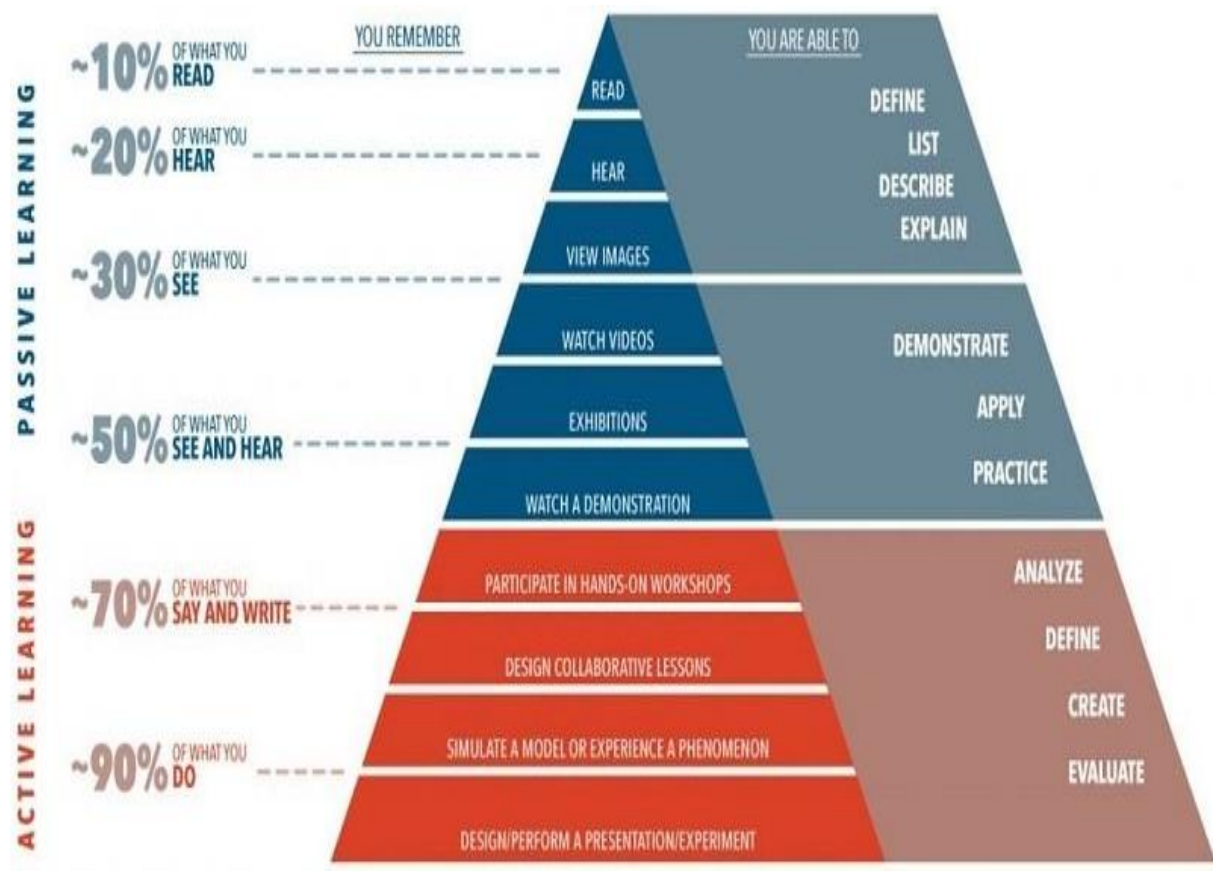

Figure 1. Dale's Pyramid Source: compiled by authors

From Figure 1 it can be seen that, according to Edgar Dale, for the most part a person is able to perceive information from what he has seen or written by himself. It should be noted that many studies confirm this fact. This pyramid makes it possible to understand that modern learning should be multi-format, that is, a student should read, see, hear and write for better learning.

Fishbein and Eisen's Theory of Reasonable Action Theory (1975) determined that human behavior is determined by his perception of the environment (Fishbein and Ajzen 1975). O'Malley and McCrow in their work noted that the efficiency of perception of educational technologies depends on the level of perception of these teaching methods, characteristics and initial knowledge of students (that is, the level of knowledge of prerequisite disciplines) (O’Malley and McCraw 2017).

Understanding the need to improve the assimilation of information led to the emergence of various strategies and techniques aimed at the study of this direction. In particular, Khalid Sabie Khamees proposed a strategy for learning English and tested it on 66 undergraduate students. The study was aimed at studying the utility of memorization as a strategy for learning English. The results showed that students used the memorization strategy mainly to enhance their vocabulary, definitions, and literary texts. Students noted that this strategy allowed them to improve their achievements in the field of learning English. It was found that understanding should take precedence over memorization. The study led to the conclusion that memorization is a low-level cognitive strategy that can be used among other high-level cognitive strategies in the process of learning English (Khamees 2016).

It is of interest to research that modern students perceive information better through familiar and understandable ways: blogs, videos, etc. In particular, Andrew K. Lui, Yannie H.Y and Sandy C. LI conducted a study on the use of compulsory blogging in the process of studying the discipline and came to the conclusion that students who 


\section{ENTREPRENEURSHIP AND SUSTAINABILITY ISSUES}

ISSN 2345-0282 (online) http://jssidoi.org/jesi/

2020 Volume 7 Number 3 (March)

http://doi.org/10.9770/jesi.2020.7.3(63)

kept a blog for a year significantly surpassed those who did not (Lui and Yannie, Sandy 2017). Despite the comment by Williams and Jacobs that it was a mistake to force students to participate in a blog for evaluations (Williams and Jacobs 2016), since this reduces the quality of education, the study showed that while students are blogging, there is a possibility that their perception of information may change in accordance with the developed tasks according to the course being studied and that the obligatory use of blogs in the course is beneficial. By applying various teaching methods, teachers are aware that many students do not enjoy all the benefits of learning available to them (Wozniak and Silveira 2017; Girdzijauskaite et al., 2019). There is a different perception of educational technologies not only because of the natural changes in education, but also because the information is perceived by students in different ways, based on their individual physiological features. The results of the study by Brian Detlora, Lorne Booker, Alexander Serenko and Heidi Julien showed that passive teaching methods are not an effective learning style that promotes positive psychological, behavioral results. While it is active learning methods that produce more positive effects (Detlora, Booker and Serenko 2017).

Pushkareva, T.P. conducted a study on improving the perception of educational material in mathematics. The results of the experiment showed that in order to increase the level of understanding of mathematical material, it is necessary to ensure the systematic use in the educational process of visual models of one particular type or their combinations and dynamic images of mathematical objects; development of methodological techniques for the inclusion in the educational process of visual models and dynamic images of mathematical objects; presence of sensory accompaniment in space and in time, i.e. dynamic visualization of information and knowledge (Pushkareva 2016). The scientific literature contains research on the stages of perception of information. In particular, according to Z.A. Kulikova, S.N. Lashchenova and others, the process of knowledge formation includes the following steps: perception of an object (identifying an object and determining its essential properties); understanding (identification of significant relationships and relationships); memorization of selected properties and relationships; active reproduction by the subject of these properties and relations. The final stage of the process of learning is their transformation - the inclusion of new knowledge in the structure of past experience and use as a means of building another new knowledge (Nurminsky and Gladysheva 2018). V.P. Bespalko suggests the following stages: understanding, recognition, reproduction, application, creativity (Bespalko 2017). S.L. Rubinshtein notes the importance of mastering the knowledge of such cognitive operations as comparison, analysis, synthesis, abstraction, generalization of conclusions by induction and deduction, etc. (Rubinstein 2015). In each case, the authors point out a creative approach to learning, as well as the advantage of understanding over simple memorization. At the same time, it is necessary to take into account the fact that, as studies show, a person forgets most of the information received. In particular, Herman Ebbingauz noted that $90 \%$ of what children learn in a classroom, they forget for 30 days, and most of them in the first hours after receiving information (Karpenko and Yaroshevskiy 2016). This fact confirms John Medina in his book "Brain Rules" (Brain Rules), noting also that knowledge is recorded not at the time of training, but as a result of repetitions after certain periods of time (Medina 2017). The brain has the ability to "relax" from receiving information "every 5-10 seconds for a fraction of a second, which is why repetition of the same information is required in various ways and lexical means" (Tovazhnyanskiy, Romanovs'kiy and Bondarenko 2016). In order to improve the degree of assimilation of information, many scientists have proposed various approaches. In particular, Dick Schmidt and Bob Björk considered the so-called "block practice", which implies the study of the same material in blocks, by repeating the information many times over a long time (Bjork 2018). In this direction, many studies were also conducted, the results of which took place in various techniques of memorizing information. For example, B. Sallivan and $\mathrm{H}$. Tompson suggest using the following recipe of repetition: the first memorization is done after 5 seconds, then after 25 seconds, after 2 minutes, after 10 minutes, after 1 hour, after 5 hours, 1 day, 5 days, 25 days, 4 months, 2 years, etc. (Sallivan and Tompson 2014) 


\section{ENTREPRENEURSHIP AND SUSTAINABILITY ISSUES}

ISSN 2345-0282 (online) http://jssidoi.org/jesi/

2020 Volume 7 Number 3 (March)

http://doi.org/10.9770/jesi.2020.7.3(63)

\section{Data and methods}

Studies of various authors regarding the degree of memorization and assimilation of information lead to the conclusion that people memorize it in various ways, each in its own way. Someone has more developed visual memory, someone has auditory. However, the fact that a person loses some of the information received (forgets) leads to an awareness of the need to enhance the digestibility of the material. In other words, research confirms that to increase the amount of memorized information requires repetition of the material under study. These facts suggested that the strategy of learning (teaching) should include, first, various forms of providing information (video lectures, presentations, story, group assignments, discussions, writing, etc.), and second, important information must be repeated at regular intervals.

If we approach the solution of the problem from a mathematical point of view, we can formulate the task of optimizing the learning strategy and form a model. At the same time, the task is to determine on the basis of its own research the information assimilation coefficient, the dependence of this coefficient on the form of information presentation, the form of training (full-time, evening), as well as to identify the most effective time for changing the type of information presentation to enhance the attention of students. In order to obtain data for the formation of a learning strategy optimization model, we conducted our own research in teaching the disciplines "Securities Market" and "Bank Accounting" in the full-time and evening training formats for two years. In total, 271 full-time students and 82 evening classes were covered. Classes were held in the format of "blending learning" and used video clips, presentations, lectures, discussions, group tasks. In order to consolidate important aspects of the topic, it was necessary to repeat these points. Naturally, at each lesson all the presented teaching methods were not applied at once, however, they alternated after a certain period of time. This alternation was arbitrary, but allowed us to estimate the coefficient of mastering the material, as well as to obtain data for assessing the dependence of the coefficient on the change in the type of presentation of information and the number of repetitions of important aspects of the topic.

To build a general strategy optimization model, a dynamic programming method was used, based on the R. Bellman's optimality principle, according to which the optimization problem will be reformulated in recursive form. The methodology of dynamic programming requires the creation of a special case of a functional equation of dynamic programming for each specific optimization problem that needs to be solved (Kormen and Leyzerson, Rivest, Shtayn 2017). For an optimization problem of the form $\operatorname{opt}_{\mathrm{d} \in \Delta}\{O(d)\} d$ is called a solution, which is selected from the set of acceptable solutions $\Delta$. The optimum $H$ is called the objective function, and $O^{*}=O\left(d^{*}\right)$ is called the optimum, where $d^{*}$ - is the value of $d \in \Delta$, for which $O(d)$ has an optimal (minimal or maximal) value. It also assumes that $d^{*}$ optimizes $O$, therefore $d^{*}=\arg \operatorname{opt}_{d}\{O(d)\}$. In dynamic programming, optimization problems consist in finding a set of solutions $\left\{d_{1}, d_{2}, \ldots, d_{n}\right\}$, which, taken together, give the optimal value $O^{*}$ of the objective function $h\left(d_{1}, d_{2}, \ldots, d_{n}\right)$. Solving such problems by enumeration, that is, by simultaneously evaluating $h\left(d_{1}, d_{2}, \ldots, d_{n}\right)$ for all possible combinations of the values of the arguments of the solution, is called the "brute force" approach, that is, this approach is clearly ineffective. Therefore, instead of making decisions at the same time, dynamic programming assumes that decisions can be made in a certain sequence $\left(d_{1}, d_{2}, \ldots, d_{n}\right)$, that is, such as:

$$
\mathrm{O}^{*}=\operatorname{opt}_{(\mathrm{d} 1, \mathrm{~d} 2, \ldots, \mathrm{dn}) \in \Delta}\left\{\mathrm{h}\left(\mathrm{d}_{1}, \mathrm{~d}_{2}, \ldots, \mathrm{d}_{\mathrm{n}}\right)\right\}=\operatorname{opt}_{\mathrm{d} 1 \in \mathrm{D} 1}\left\{\operatorname{opt}_{\mathrm{d} 2 \in \mathrm{D} 2}\left\{\ldots\left\{\operatorname{opt}_{\mathrm{dn} \in \operatorname{Dn}}\left\{\mathrm{h}\left(\mathrm{d}_{1}, \mathrm{~d}_{2}, \ldots, \mathrm{d}_{\mathrm{n}}\right)\right\}\right\} \ldots\right\}\right\}
$$

These are the so-called sequential decision-making processes, where the ordered set $\left(d_{1}, d_{2}, \ldots, d_{n}\right)$ belongs to a certain decision-making space $\Delta=\mathrm{D}_{1} \times \mathrm{D}_{2} \times \ldots \times \mathrm{D}_{\mathrm{n}}$ for $\mathrm{d}_{\mathrm{i}} \in \mathrm{D}_{\mathrm{i}}$. Examples of decision areas: $\Delta=\mathrm{B}^{\mathrm{n}}$, a special case of Boolean solutions, where each set of solutions $\mathrm{D}_{\mathrm{i}}$ equals $\mathrm{B}=\{0,1\}$; and $\Delta=\Pi(\mathrm{D})$ - is the permutation of the set of acceptable solutions D (Mauch 2017). 
The coefficient of learning was calculated as the ratio of the correct answers on the test questions for each lesson to the total number of questions in the test. For each lesson, the weighted average value of the learning coefficient was determined, where the number of students with a certain coefficient value was the weight. At the same time, the weighted average values of the learning coefficients for the convenience of calculations were grouped in accordance with the result of reductions to the hundredth. For example, if a value of 0.973 was obtained, then it was assigned to the group 0.97 , the value 0.942 to the group 0.94 , and so on.

For each lesson, students were asked test questions of the previous lesson to determine the level of mastering the topic. Each test consisted of 5 questions with five possible answers. There were 7 days between classes, that is, this is the period between taking the information and checking for its mastering. Each topic was divided into 4 main questions. In turn, the dependence of the assimilation coefficient on the change of the type of training, as well as the number of repetitions of the main aspects of the topic were estimated using the multiple regression equation. At the same time, the number of types of information provided was changed.

Calculations were carried out in Excel.

The results of the study. To obtain the regression equation, we define for the beginning the vector of the regression coefficients. According to the method of least squares, the vector is obtained from the multiplication of matrices in the expression: $S=\left(x^{\mathrm{T}} \mathrm{x}\right)^{-1} \mathrm{x}^{\mathrm{T}} \mathrm{y}$.

The $\mathrm{x}^{\mathrm{T}} \mathrm{x}$ matrix is as follows:

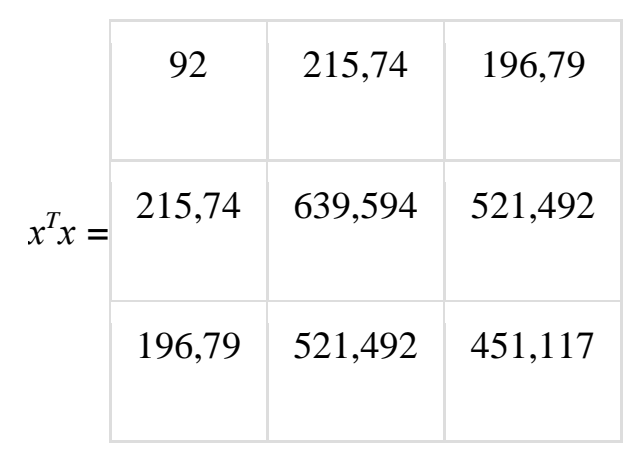

In the matrix $x^{T} x$, for example, the number 215,74 , lying at the intersection of the 1 st row and the 2nd column, is obtained as the sum of the products of the elements of the 1st row of the matrix $x^{T}$ and the 2nd column of the matrix $x$.

The matrix $x^{T} y$ has the following form:

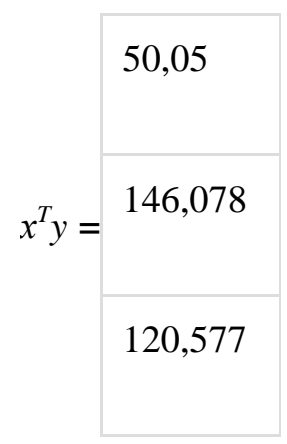

Find the inverse matrix $\left(x^{T} x\right)^{-1}$, which will have the following form: 


\begin{tabular}{|c|c|c|c|}
\hline \multirow{3}{*}{$\left(x^{T} x\right)^{-1}=$} & 0,417 & 0,133 & $-0,336$ \\
\hline & 0,133 & 0,0698 & $-0,139$ \\
\hline & $-0,336$ & $-0,139$ & 0,309 \\
\hline
\end{tabular}

As a result of matrix multiplication, the vector of regression coefficient estimates will be equal to:

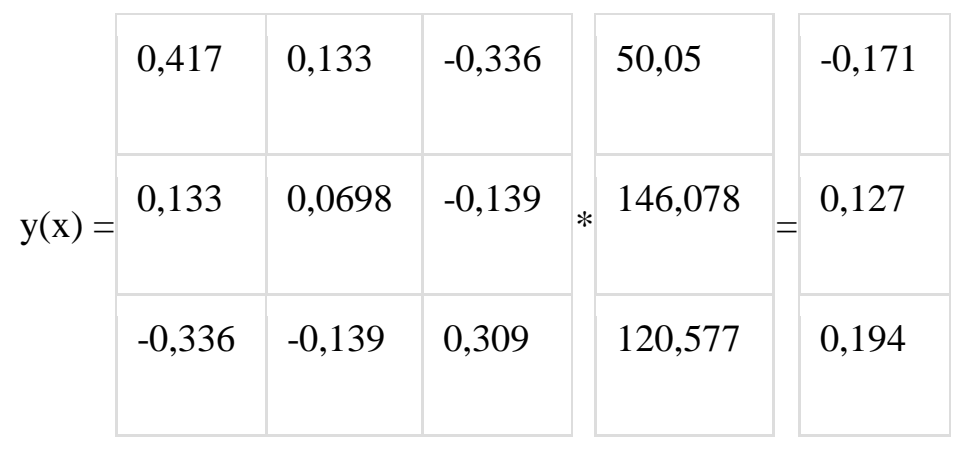

So, the regression equation describing the dependence of the number of repetitions during one occupation of important aspects and the number of changes in the type of presentation of the material has the following form:

$$
y=-0,1708+0,1275 x_{1}+0,1945 x_{2}
$$

where

$y$ - learning rate;

$x_{1}$ - number of repetitions of important aspects of a topic;

$x_{2}-$ the number of changes in the type of presentation material.

Correlation coefficients and indicators of variances are presented in table 1.

Table 1. Indicators of correlations and dispersions

\begin{tabular}{|c|c|c|c|c|c|c|c|c|}
\hline $\begin{array}{c}\text { Signs of } x \\
\text { и } y\end{array}$ & $\sum x_{i}$ & $\bar{x}=\frac{\sum x_{i}}{n}$ & $\sum y_{i}$ & $\bar{y}=\frac{\sum y_{i}}{n}$ & $\sum x_{i} y_{i}$ & $\overline{x y}=\frac{\sum x_{i} y_{i}}{n}$ & $D(x)$ & $D(y)$ \\
\hline for $y$ и $x_{1}$ & 215,74 & 2,345 & 50,05 & 0,544 & 146,078 & 1,588 & 1,453 & 0,0715 \\
\hline for $y$ и $x_{2}$ & 196,79 & 2,139 & 50,05 & 0,544 & 120,577 & 1,311 & 0,328 & 0,0715 \\
\hline for $x_{1}$ и $x_{2}$ & 196,79 & 2,139 & 215,74 & 2,345 & 521,492 & 5,668 & 0,328 & 1,453 \\
\hline
\end{tabular}

Source: compiled and calculated by authors 
In this case, the paired correlation coefficients have the following values:

$$
\begin{aligned}
& r_{x_{1} y}=\frac{1,59-2,35 * 0,54}{1,21 * 0,27}=0,968 \\
& r_{x_{2} y}=\frac{1,31-2,14 * 0,54}{0,57 * 0,27}=0,959 \\
& r_{x_{1} x_{2}}=\frac{5,67-2,14 * 2,35}{0,57 * 1,21}=0,945
\end{aligned}
$$

Assess the $\beta$-coefficients:

$$
\begin{aligned}
& \beta_{1}=\frac{0,968-0,959 * 0,945}{1-0,945^{2}}=0,575 \\
& \beta_{2}=\frac{0,959-0,968 * 0,945}{1-0,945^{2}}=0,416
\end{aligned}
$$

The multiple correlation index is:

$$
R=\sqrt{1-\frac{0,29}{6,58}}=0,9777
$$

Since $\mathrm{R}$ is close to 1 , the connection between the resulting indicator $\mathrm{y}$ and the factors $\mathrm{x}_{\mathrm{i}}$ is quite strong.

The coefficient of determination is $R^{2}=0,9559$. Since $R^{2}$ is close to 1 , the resulting regression equation almost completely explains the behavior of the indicator $\mathrm{y}$.

The results of dynamic programming allowed us to obtain the following distribution of resources $x_{1}$ and $x_{2}$ (table $2)$.

Table 2. Distribution of the number of repetitions and change the type of presentation of the material (optimal values)

\begin{tabular}{|c|c|c|}
\hline Learning rate & $\begin{array}{c}\text { The number of repetitions of important } \\
\text { aspects of a topic }\end{array}$ & $\begin{array}{c}\text { The frequency of changing the type of } \\
\text { training }\end{array}$ \\
\hline 1 & 3,98 & 2,66 \\
\hline 0,99 & 3,98 & 2,64 \\
\hline 0,98 & 3,98 & 2,77 \\
\hline 0,97 & 3,94 & 2,76 \\
\hline
\end{tabular}




\begin{tabular}{|c|c|c|}
\hline 0,96 & 3,97 & 2,78 \\
\hline 0,95 & 3,98 & 2,89 \\
\hline 0,94 & 3,97 & 2,67 \\
\hline 0,93 & 3,95 & 2,79 \\
\hline 0,92 & 3,77 & 2,81 \\
\hline 0,91 & 3,87 & 2,56 \\
\hline 0,9 & 3,56 & 2,78 \\
\hline 0,89 & 3,67 & 2,77 \\
\hline 0,88 & 3,55 & 3 \\
\hline 0,87 & 3,54 & 2,57 \\
\hline 0,86 & 3,28 & 2,56 \\
\hline 0,85 & 3,65 & 2,55 \\
\hline 0,84 & 3,89 & 2,58 \\
\hline 0,83 & 3,77 & 2,57 \\
\hline 0,82 & 3,9 & 2,59 \\
\hline 0,81 & 3,82 & 2,67 \\
\hline 0,8 & 3,45 & 2,66 \\
\hline
\end{tabular}

Source: compiled and calculated by authors

\section{Results}

The results of the study of the influence of the number of repetitions of important aspects of the topic and the number of changes in the presentation of information for students on the coefficient of mastering the material suggest that an increase in $x_{1}$ by 1 unit of measurement leads to an increase in the coefficient of mastering by an average of 0,127 . At the same time, an increase of $x_{2}$ by 1 unit of measurement leads to an increase in the absorption coefficient by an average of 0,194 .

These data show that the effect of changing the type of presentation of the material is higher than the number of simple repetitions, although it is also impossible to exaggerate the importance of the latter. At the same time, when comparing the coefficients $\beta_{1}$ and $\beta_{2}$, it is noticeable that $\beta_{1}=0,575$ is higher. This indicates that factor has a strong influence on the result of assimilation. It was established that in the situation under study, 95,59\% of the total variability of the assimilation coefficient is explained by the change in the indicated factors. At the same time, the parameters of the model are statistically significant. Indeed, as practice has shown, when changing the type of presentation of the material, for example, from presentation to video, to group work, to discussion, etc., there was some revival of the audience, attraction and increased concentration, which apparently made it possible to better understand the issue under consideration. At the same time, the presence of repetitions of important aspects of the topic increases the coefficient of learning by another 0,127 . 


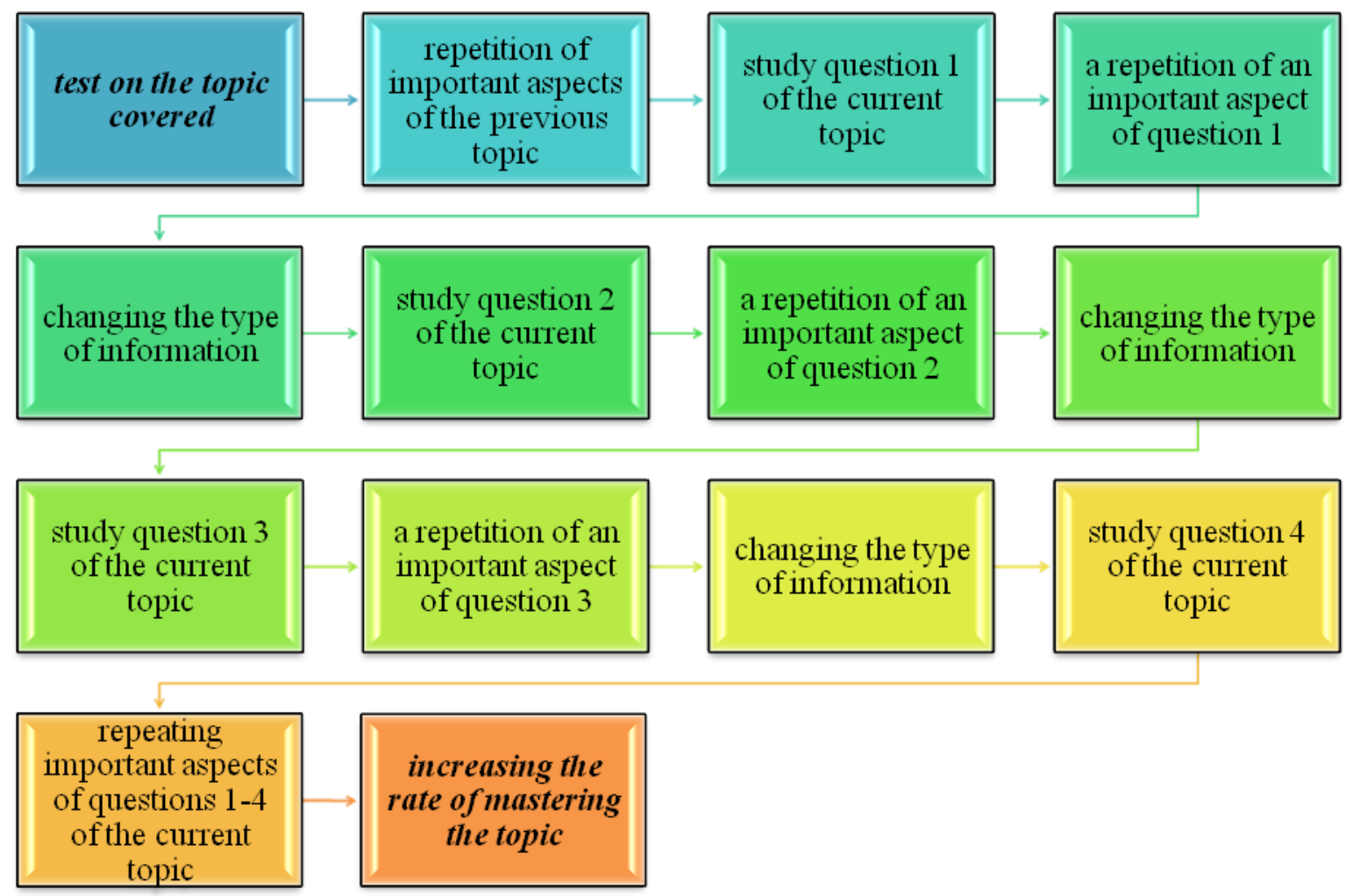

Figure 2. The optimal learning strategy, according to the authors Source: compiled by authors

The results of table 2 clearly show that a higher rate of assimilation of information is provided with an appropriate number of repetitions and a change in the type of presentation of the material. Considering the fact that the teacher spends about 5-10 minutes out of 50 for various activities not related to the transfer of information (roll call of students, video connection, etc.), taking into account the fact that the classes were tested for 5 minutes to check the mastery of the material of the previous topic, the net learning time remains about 40 minutes. When calculating 4 iterations to study a topic, it turns out that after considering each question, it is necessary to repeat the main aspects of the topic and change the type of presentation of the material. As a result, the optimal learning strategy will be as follows.

As the results of testing in practice of this strategy have shown, such an approach significantly increases the degree of material assimilation, and regular repetitions with a change in the type of material presentation reinforce the quality of training.

\section{Conclusions}

However, for the effective implementation of this strategy requires the introduction of some effort and development from the teacher. In particular, before implementing this strategy, the following should be implemented:

1) Break the topic down into basic questions (it's not a trifle here, it's important that the questions cover the most significant aspects of the topic, the remaining points (less important) should flow from the basic questions; 


\section{ENTREPRENEURSHIP AND SUSTAINABILITY ISSUES}

ISSN 2345-0282 (online) http://jssidoi.org/jesi/

2020 Volume 7 Number 3 (March)

http://doi.org/10.9770/jesi.2020.7.3(63)

2) To determine the types of information provision (video materials, interactive presentations, group classes, exercises, discussions, etc.);

3) At each lesson, it is necessary to develop a test on the previous topic (as the own practice of the authors showed, 5 questions are enough, but the most important ones);

4) Video material and other types of material presentation should cover only one question or, better, part of the question; this video should not be more than 2 minutes);

5) It is imperative to repeat important aspects of the questions, in this case, it is necessary to indicate them briefly and clearly;

6) Practical exercises should be structured in such a way that the students themselves either prescribe questions of the topic or discuss them or exercises.

The proposed training strategy was tested in practice when conducting the following disciplines: "Securities Market" and "Bank Accounting". In the future, it is intended to conduct further research regarding the assessment of the quality of education, the definition of criteria for assessing assignments that most fully allow for objectively assessing the results of students' work, excluding plagiarism, cheating and "using" the knowledge of other students.

\section{References}

Bespalko, V.P. 2017. The components of educational technology. Moscow. 192 p.

Bjork, R.A. 2018. Being Suspicious of the Sense of Ease and Undeterred by the Sense of Difficulty: Looking Back at Schmidt and Bjork. Perspectives on Psychological Science, 13(2), 146-148.

Detlora, B., Booker, L., Serenko, A. 2017. Student perceptions of information literacy instruction: The importance of active learning. Education for Information, 29(67), 147-161.

Fishbein, M., Ajzen, I. 1975. Belief, Attitude, Intention, and Behavior: An Introduction to Theory and Research. Addison-Wesley, Moscow, $335 \mathrm{p}$.

Girdzijauskaite, E., Radzeviciene, A., Jakubavicius, A. 2019. Impact of international branch campus KPIs on the university competitiveness: FARE method. Insights into Regional Development, 1(2), 171-180. https://doi.org/10.9770/ird.2019.1.2(7)

Karpenko, L.A., Yaroshevskiy, M.G. The history of psychology in persons. Moscow: PER SE, 784 p.

Karpf, A. 2014. The Human Voice and the Texture of Experience. Oral History, 2(42), 50-55.

Khamees, K.S. 2016. An Evaluative Study of Memorization as a Strategy for Learning English. International Journal of English Linguistics, 4(6), 1923-1930.

Kormen, T., Leyzerson C.H., Rivest R., Shtayn K. 2017. Dynamic programming. Algorithms: construction and analysis. Moscow: Williams, $1296 \mathrm{p}$.

Lui, A., Yannie H., Sandy C. 2017. A Study on the Perception of Students towards Educational Weblogs. Informatics in Education, 2(5), 233-254.

Mauch, L.H. 2017. Introduction to Dynamic Programming. Studies in Computational intelligence, 3(38), 3-43.

Medina, J.2017. Brain Rules (Updated and Expanded): 12 Principles for Surviving and Thriving at Work, Home, and School Second Edition Science, 320 p.

Mehrabian, A., Ferris, S. 1967. Inference of Attitudes from Nonverbal Communication in Two Channels. Journal of Consulting Psychology, 3 (31), 248-258.

Nurminsky, I.I., Gladysheva, N.K. 2018. Statistical patterns of formation of knowledge and skills of students. Moscow. 224 p. 


\section{ENTREPRENEURSHIP AND SUSTAINABILITY ISSUES}

ISSN 2345-0282 (online) http://jssidoi.org/jesi/

2020 Volume 7 Number 3 (March)

http://doi.org/10.9770/jesi.2020.7.3(63)

O’Malley, J., McCraw, H. 2017. Students' perceptions of distance learning, online learning, and the traditional classroom. Online Journal of Distance Learning Administration, 2(4), 33-39.

Pushkareva, T.P. 2016. Improving the understanding of educational material in teaching students mathematics. Open Education, 4(17), 2431.

Rubinstein, S. L. 2015. Fundamentals of General Psychology. SPb: Peter. 723 p.

Sallivan, B., Tompson, K.H. 2014. Effekt plato. How to overcome stagnation and move on. Moscow: Mann, 320 p.

Samreen, A., Malik, K. 2012. Use of audio visual aids for effective teaching of biology at secondary schools level. Elixir Leadership Management, 7(50), 10597-10605.

Tovazhnyanskiy, L.L., Romanovs'kiy, O.G., Bondarenko, V.V. 2016. Fundamentals of Higher Education Pedagogy. Kharkív: NTU, 600 p. Williams, J.B., Jacobs, K. 2016. Exploring the use of Blogs as learning spaces in the higher education sector. Australasian Journal of Educational Technology, 20(2), 232-247.

Wozniak, H., Silveira, S. 2017. Online discussions: Promoting effective student-to-student interaction. Moscow: ASCILITE. 956-960 pp. Zhuk, Y., Krasovskiy, V., Tonkonogov, B.A., Grigor'yeva, Ye. 2016. Designing distance courses in the light of further education of specialis. Ecology journal, 3(37), 19-23.

Elvira RUZIEVA is Candidate of Economic Sciences, Associate professor of Narxoz University, Almaty, Kazakhstan. Research interests: finance, insurance, insurance companies, economy.

ORCID ID: orcid.org/0000-0001-9120-7776

Aliya NURGALIYEVA is Candidate of Economic Sciences, Associate professor of Narxoz University, Almaty, Kazakhstan. Research interests: finance, insurance, insurance companies, economy.

ORCID ID: orcid.org/0000-0001-6044-6926

Botagoz DUISENBAYEVA is Candidate of Economic Sciences, Associate professor of Kazakh-Russian International University, Aktobe, Kazakhstan. Research interests: finance, insurance, insurance companies, economy, entrepreneurship, innovation.

ORCID ID: orcid.org/0000-0001-5959-7946

Dina KULUMBETOVA is Candidate of Economic Sciences, Associate professor of Kazakh-Russian International University, Aktobe, Kazakhstan. Research interests: finance, insurance, insurance companies, economy, entrepreneurship, innovation.

ORCID ID: orcid.org/0000-0002-5566-7107

Mira ZHAPBARKHANOVA is Candidate of Economic Sciences, Associate professor of Narxoz University, Almaty, Kazakhstan. Research interests: finance, insurance, insurance companies, economy.

ORCID ID: orcid.org/0000-0001-5448-3827

Register for an ORCID ID:

https://orcid.org/register

Copyright (C) 2020 by author(s) and VsI Entrepreneurship and Sustainability Center

This work is licensed under the Creative Commons Attribution International License (CC BY).

http://creativecommons.org/licenses/by/4.0/

CC) (i) Open Access 